\title{
Urinary tract infection: a comparison of four methods of investigation
}

\author{
J M Smellie, S P A Rigden, N P Prescod
}

\begin{abstract}
The optimal regimen for investigating children with urinary tract infection (UTI) remains uncertain. Ultrasonography, contrast micturating cystourethrography (MCU), intravenous urography (IVU), and technetium-99m dimercaptosuccinic acid (DMSA) studies were performed in 58 children with UTI under 14 years of age attending two teaching hospitals and the results compared. All four investigations were normal in 12 children. In 36 with vesicoureteric reflux (VUR) on MCU, dilatation was reported on ultrasonography in eight children. Radiological renal scarring was seen in 20 children; it was suspected on ultrasonography in nine, with dilatation alone in four, and a normal report in seven. Duplex kidneys identified on IVU were unrecognised on ultrasonography or DMSA studies; ultrasonography showed no change corresponding to presumed acute defects on DMSA studies that later resolved. Disparities were observed at all ages. This study suggests that ultrasonography is unreliable in detecting VUR, renal scarring, or inflammatory change and, alone, is inadequate for investigating UTI in children.
\end{abstract}

(Arch Dis Child 1995; 72: 247-250)

Keywords: urinary tract infection, vesicoureteric reflux, renal scarring.

Department of Paediatrics, University College Hospital, London

J M Smellie

N P Prescod

Department of Paediatric Nephrology, Guy's Hospital, London

S P A Rigden

Correspondence to:

Dr S P A Rigden,

Dr S P A Rigden,

Department of Paediatric

Nephrology, Guy's Hospital,

SE1 Thoma

Accepted 18 August 1994
Many opinions have been expressed about the investigation of children with urinary tract infection (UTI). ${ }^{1-5}$ However, there remains uncertainty about the most appropriate means of obtaining the necessary information for management while protecting the child from radiation or invasive procedures. It has been widely suggested that ultrasonography, with the advantage of being non-invasive and without radiation, might be substituted for other methods of imaging of both upper and lower urinary tract.

In view of the number of children presenting in our departments with serious and potentially avoidable problems, ${ }^{6}$ particularly from misinterpretation of ultrasonography reports, and the lack until recently of comparative studies of different investigative methods, we set up a study to compare four different methods of investigating children with UTI. The results of ultrasonography were compared with contrast micturating cystourethrography (MCU), intravenous urography (IVU), and nuclear imaging using technetium-99m dimercaptosuccinic acid (DMSA). We report the findings in 58 children seen with symptomatic UTI between the years 1986 and 1991 at Guy's and University College Hospitals and who underwent all four investigations.

\section{Subjects and methods}

Children were included who were aged less than 14 years and who had at least one bacteriologically proved urinary tract infection. It was planned to complete ultrasonography, MCU, IVU, and DMSA studies within a period of three months. Standard methods were used and nuclear imaging, ultrasonography, and contrast radiology were each carried out in independent departments, the request forms stating only the history of UTI. At University College Hospital the IVU and MCU were each limited to four films. The report of renal tract ultrasonography was correlated with the appearances and reports of the other investigations. The study had the ethical approval of both hospitals.

Fifty eight children, 12 boys and 46 girls, aged 1 month to 13.5 years (median 3.3 years) entered the study. There were 42 primary and secondary referrals and 16 were tertiary referrals from other hospitals. All four

Table 1 Age, sex, and history of 58 children investigated after symptomatic UT

\begin{tabular}{llccc}
\hline & & & \multicolumn{2}{c}{ History of UTI } \\
\cline { 3 - 5 } $\begin{array}{l}\text { Age } \\
\text { (years) }\end{array}$ & Total & $M / F$ & $\begin{array}{l}\text { Presumed } \\
\text { first }\end{array}$ & Recurrent \\
\hline $0<2$ & 19 & $7 / 12$ & 13 & 6 \\
$2<5$ & 22 & $5 / 17$ & 8 & 14 \\
$5+$ & 17 & $0 / 17$ & 8 & 9 \\
Total & 58 & $12 / 46$ & 29 & 29 \\
\hline
\end{tabular}


Table 2 Comparison of reports of ultrasonography with the results of other imaging methods in 58 children with symptomatic UTI

\begin{tabular}{lllc}
\hline & & \multicolumn{2}{c}{ Report of ultrasonography } \\
\cline { 4 - 4 } MCU/IVU/DMSA studies & Total & Normal & Abnormal \\
\hline All investigations normal & $18^{\star}$ & 16 & $2 \dagger$ \\
$\begin{array}{l}\text { More than one investigation } \\
\text { abnormal }\end{array}$ & 40 & 23 & 17 \\
Total & 58 & 39 & 19 \\
\hline
\end{tabular}

* These include six children in whom the initial DMSA study was abnormal but later resolved after treatment ('transient' changes). +Both showed ureteric dilatation only.

Table 3 Reports of ultrasonography in relation to age at study

\begin{tabular}{|c|c|c|c|c|c|c|}
\hline \multirow{3}{*}{$\begin{array}{l}\begin{array}{l}\text { Age } \\
\text { (years) }\end{array} \\
0<2 \\
2<5 \\
5+\end{array}$} & \multicolumn{4}{|c|}{ Findings reported on ultrasonography } & \multirow{2}{*}{\multicolumn{2}{|c|}{ Total }} \\
\hline & \multicolumn{2}{|c|}{$\begin{array}{l}\text { No dilatation, } \\
\text { normal kidneys }\end{array}$} & \multicolumn{2}{|c|}{$\begin{array}{l}\text { Dilatation/renal } \\
\text { abnormality }\end{array}$} & & \\
\hline & $\begin{array}{l}12 \\
15 \text { (1) } \\
12 \text { (4) }\end{array}$ & $\begin{array}{r}(10) \\
(7) \\
(6)\end{array}$ & $\begin{array}{l}7^{\star}(1) \\
7^{\star} \\
5\end{array}$ & $\begin{array}{l}(6) \\
(6) \\
(5)\end{array}$ & $\begin{array}{l}19 \text { (1) } \\
22 \text { (1) } \\
17 \text { (4) }\end{array}$ & $\begin{array}{l}(16) \\
(13) \\
(11)\end{array}$ \\
\hline & 39 (5) & (23) & 19 (1) & (17) & 58 (6) & $(40)$ \\
\hline
\end{tabular}

Parentheses indicate abnormal findings on IVU, MCU, or a DMSA study.

Circles indicate the six children with transient DMSA study changes, who are included among those with normal radiological findings.

*Indicates the two children with ureteric dilatation only.

investigations were carried out within three months of infection in 47 children. In 11 they were completed over a period of 4-12 months. Apart from seven ultrasound scans undertaken in the referring hospitals, the studies were all performed at Guy's or University College/Middlesex Hospitals.

The urinary tract infection was treated rapidly in all children and low dose antibacterial prophylaxis continued at least until investigations were completed.

\section{Results}

The age at the time of investigation, sex and history of urinary infection of the 58 children studied are shown in table 1 . In 12 children, all four investigations were normal and in 46 children some abnormality was reported on one or more studies. Vesicoureteric reflux (VUR) was seen on MCU in 36 children (18 with scarred and three with duplex kidneys); the IVU showed renal scarring in 20 children (bilateral in eight) and duplex kidneys in five (bilateral in one). Both IVU and MCU were normal in 18 children.

On the DMSA study defects of isotope uptake or a difference in percentage contribution to total renal function of more than $10 \%$ were noted in 26 children. In six of these, all girls without VUR, there were minor defects of isotope uptake, initially reported as scars, which, after treatment, disappeared within 6-12 months and corresponded with a normal IVU. We have termed these transient changes. Nineteen of the 20 children with renal scarring on IVU showed defects of DMSA uptake. One with a small left upper pole scar on IVU showed no focal defect and symmetrical function. Renal scarring was also suggested on the DMSA study report, but not confirmed on IVU, in one kidney of the child with bilateral duplex kidneys, each of which contributed $50 \%$ of total function. The four with unilateral duplex kidneys had normal DMSA study images with a difference of less than $10 \%$ divided function.

The reports of ultrasonography were normal in 39 children (five boys) and abnormal in 19 (seven boys). Among the latter, dilatation of the urinary tract was reported in nine, a renal abnormality in nine, and both were reported in one child.

The correlations of these findings are presented in tables $2-5$. Table 2 shows the overall comparison between ultrasonography and the other imaging and table 3 relates the findings to the age at study and includes the abnormal findings on IVU, MCU, and DMSA studies. (The six children with 'transient' DMSA changes that had resolved on a repeat DMSA study are here analysed with the normals.) Disparities between ultrasonography and other imaging methods were seen in all age groups.

Thus there were 23 children (three boys) with false negative findings on ultrasonography among 40 with abnormalities of the renal tract identified on one or more of the other imaging methods. In addition no increase in echogenicity was detected in six children with transient DMSA study abnormalities. There were two apparently false positive results with ureteric dilatation not confirmed by MCU. In one of these, an infant on prophylaxis, cystography was

Table 4 Details of findings reported on ultrasonography in 58 children related to other imaging, where IVU, MCU, and $D M S A$ studies were all normal in 12, 'transient' changes were seen on the DMSA study in six, and an abnormality was seen in one or more in 40 children

\begin{tabular}{|c|c|c|c|c|c|c|c|}
\hline \multirow[b]{3}{*}{ Investigation } & \multirow[b]{3}{*}{$\begin{array}{l}\text { Results } \\
\text { (MCU/IVU/DMSA studies) }\end{array}$} & \multirow[b]{3}{*}{ Total } & \multicolumn{5}{|c|}{ Findings reported on ultrasonography } \\
\hline & & & \multirow[b]{2}{*}{ Normal } & \multirow[b]{2}{*}{ Abnormal } & \multicolumn{3}{|c|}{ Abnormality reported } \\
\hline & & & & & $\begin{array}{l}\text { Dilatation } \\
\text { only }\end{array}$ & $\begin{array}{l}\text { Renal } \\
\text { only }\end{array}$ & $\begin{array}{l}\text { Renal+ } \\
\text { dilatation }\end{array}$ \\
\hline IVU/MCU/DMSA studies & $\begin{array}{l}\text { Normal findings on all three } \\
\text { investigations }\end{array}$ & 12 & 10 & 2 & 2 & 0 & 0 \\
\hline $\mathrm{MCU}$ & VUR (all grades) & 36 & 21 & $15^{\star}$ & 7 & $7^{\star}$ & 1 \\
\hline IVU/DMSA studies & Renal scarring & 20 & 7 & 13 & 4 & 8 & 1 \\
\hline IVU & Duplex kidney & 5 & 5 & 0 & 0 & 0 & 0 \\
\hline DMSA study & 'Transient' changes & 6 & 6 & 0 & 0 & 0 & 0 \\
\hline
\end{tabular}

*Including a boy aged 3 years: global reduction in right kidney size but no dilatation reported on ultrasonography. Right VUR and normal kidney on other imaging. 
Table 5 Maximum severity of VUR in one or both ureters in 36 children with VUR on MCU related to age and ultrasonography reports. Severe reflux was overlooked on ultrasonography in all age groups

\begin{tabular}{|c|c|c|c|c|c|c|c|c|c|}
\hline \multirow[b]{3}{*}{$\begin{array}{l}\text { Age } \\
\text { (years) }\end{array}$} & \multirow{2}{*}{\multicolumn{2}{|c|}{$\begin{array}{l}\text { Dilatation on } \\
\text { ultrasonography }\end{array}$}} & \multicolumn{7}{|c|}{$V U R$ on $M C U$} \\
\hline & & & \multirow[b]{2}{*}{$\begin{array}{l}\text { Total } \\
\text { No }\end{array}$} & \multicolumn{2}{|c|}{$\begin{array}{l}\text { Minimal } \\
\left.\text { (grade } I^{\star}\right)\end{array}$} & \multicolumn{2}{|c|}{$\begin{array}{l}\text { Up to kidney } \\
\left.\text { (grade } I I^{\star}\right)\end{array}$} & \multicolumn{2}{|c|}{$\begin{array}{l}\text { Severe with dilatation } \\
\left.\text { (grade III }-V^{\star}\right)\end{array}$} \\
\hline & $\begin{array}{l}\text { Not } \\
\text { found }\end{array}$ & Found & & No & $\begin{array}{l}\text { Dilatation on } \\
\text { ultrasonography }\end{array}$ & No & $\begin{array}{l}\text { Dilatation on } \\
\text { ultrasonography }\end{array}$ & No & $\begin{array}{l}\text { Dilatation on } \\
\text { ultrasonography }\end{array}$ \\
\hline $\begin{array}{l}0<2 \\
2<5 \\
5+\end{array}$ & $\begin{array}{r}10 \\
11 \\
7\end{array}$ & $\begin{array}{l}4 \\
2 \\
2\end{array}$ & $\begin{array}{r}14 \\
13 \\
9\end{array}$ & $\begin{array}{l}0 \\
0 \\
4\end{array}$ & $\begin{array}{l}0 \\
0 \\
1\end{array}$ & $\begin{array}{l}7 \\
8 \\
1\end{array}$ & $\begin{array}{l}1 \\
0 \\
0\end{array}$ & $\begin{array}{l}7 \\
5 \\
4\end{array}$ & $\begin{array}{l}3 \\
2 \\
1\end{array}$ \\
\hline Total & 28 & 8 & 36 & 4 & 1 & 16 & 1 & 16 & 6 \\
\hline
\end{tabular}

ॠInternational reflux grading.

delayed for one year and VUR might have resolved in the interval. In the other, a 4 year old boy, no VUR was seen on MCU within one month but bilateral Hutch saccules were seen suggesting earlier reflux. Overall, ultrasonography had a sensitivity of $37 \%$ and a specificity of $83 \%$ for urinary tract abnormalities. If the six children with transient DMSA study changes are included among the normal results of other imaging, the overall sensitivity and specificity of ultrasonography were $42.5 \%$ and $89 \%$ respectively.

Twenty two of the 29 children studied after a presumed first infection had a normal ultrasonography report that was not significantly different from the 29 with a history of recurrence, among whom 17 had a normal report.

\section{RENAL SCARRING: RESULTS OF}

\section{ULTRASONOGRAPHY}

Among the 20 children with radiological renal scarring, a renal abnormality or asymmetry in size was reported on ultrasonography in nine children, although it was underestimated in five of these. In four others, only ureteric dilatation was reported and in the remaining seven, four with bilateral scarring, no abnormality was reported on ultrasonography. There was a false positive report of unilateral global renal shrinkage without any dilatation in a boy of 4 with normal IVU and DMSA study but bilateral reflux. As already stated no increase in echogenicity or asymmetry in size was seen on ultrasonography performed within one month of the DMSA study in the six children with transient focal defects. The sensitivity and specificity of ultrasonography for the detection of renal abnormalities in this series were $42 \%$ and $96 \%$ respectively.

\section{VUR: RESULTS OF ULTRASONOGRAPHY}

Dilatation on ultrasonography may suggest VUR but it can only be confirmed by cystography. As seen in table 4, the report of ultrasonography was normal in 21 of the 36 children with reflux on MCU. These included 15 of the 24 children with bilateral reflux and six of the 16 with severe reflux associated with dilatation on MCU (international grade III-V). In seven children with VUR no dilatation was reported, although a renal abnormality was noted. Reflux was demonstrated on MCU in eight of the 10 children with ureteric or renal pelvic dilatation on ultrasonography. (The other two apparent false positives may have had VUR which had resolved before the MCU was performed, as already mentioned.) Thus ultrasonography showed a sensitivity of $42 \%$ and a specificity of $91 \%$ for the detection of VUR in this series.

In the 36 children with reflux on cystography, the relation between the more severe grade of reflux in each child and the ultrasonography report at the age at study is shown in table 5. As would be expected, severe reflux was more common in infants and milder reflux was only seen in the oldest group. Nevertheless dilatation was only reported on ultrasonography in six of the 16 children with severe reflux (including only one of the four children aged 5 and over), while four had only renal abnormalities and in six no abnormality was reported.

\section{TIMING OF INVESTIGATIONS}

Among the 11 children in whom the investigations were performed over an extended period of 4-12 months, reflux might have resolved spontaneously in one child, between the report of ureteric dilatation on ultrasonography and the negative cystogram 10 months later. In another child, a renal scar could have developed between the time of ultrasonography and the renal studies. If these two children are excluded, the overall sensitivity and specificity for detection of a renal tract abnormality by ultrasonography would be $39 \%$ and $83 \%$ respectively.

\section{Discussion}

Investigation of the child's urinary tract after infection is undertaken to discover the cause of the infection in order to prevent recurrence and to ascertain whether the kidneys are normal, involved, or at risk of renal scarring; whether there is VUR; and to identify stones or outflow obstruction requiring surgical treatment.

A high proportion of the children with symptomatic UTI included in this study had abnormal renal tract findings. There are 
several reasons for this: half of them had a history of recurrent UTI and 16 of the 58 were tertiary referrals to a paediatric renal outpatient clinic.

There was a high false negative rate on ultrasonography. No dilatation was reported in 28 of 36 children with VUR, although a report of a renal abnormality in seven would have led to further investigation. The extent and severity of VUR were underestimated in all age groups. No renal abnormality was noted on ultrasonography in 11 of the 20 children with scarring or five with duplex kidneys. There was, however, a report of dilatation alone on ultrasonography in four of the 20 children with scarred kidneys. There was no increased echogenicity or renal size recorded on ultrasonography in the six children with abnormal DMSA study images that resolved after treatment and that were presumed to be due to acute pyelonephritis. ${ }^{7}$ Disparity between ultrasonography reports and other imaging occurred in all age groups.

This study clearly confirms previous findings that ultrasonography alone is not generally adequate for the investigation of childhood UTI. ${ }^{6-9}$ Ultrasonography is valuable in identifying fixed dilatation due to obstruction to outflow which is now usually predicted by antenatal ultrasonography and should be diagnosed in infancy. ${ }^{1011}$ However, UTI is not a common presentation for obstruction after infancy and was not seen in any of the 58 children studied. The technique, which detects changes in interface, is not adequate to detect inflammatory change, small scarred areas, or the intermittent dilatation of VUR. Indeed, despite its attraction as a non-invasive technique without radiation, its place in the 'screening' of the child's urinary tract after infancy must at present be seriously questioned. This study extended over several years but even with improved skills and equipment the technique remains observer dependent, cannot readily be reviewed retrospectively, can provide false reassurance when negative and, when an abnormal result is reported, further investigation involving additional hospital visits is needed to determine the nature of the abnormality. A report of 'no abnormality seen' should not be interpreted as 'normal'.

With few exceptions these results were obtained in two teaching hospitals where the investigations were carried out as part of routine clinical care and not as a study performed by designated imagers. It is possible that better results can be obtained in centres with specialised paediatric renal ultrasonographers but these are not generally available.

There was in general good agreement between the IVU and DMSA study findings. Six children had an abnormal DMSA study image but a normal IVU and MCU. UTI was treated rapidly in all six and on follow up all six DMSA studies had returned to normal. One child with minor upper pole scarring on IVU had a normal DMSA study image with symmetrical function. Because of their familial association with VUR, ${ }^{12}$ it is important to diagnose duplex kidneys which were unrecognised by DMSA studies and ultrasonography in the five children with duplex kidneys in this study. Reports of other studies comparing different imaging modalities have reached varying conclusions. ${ }^{1813}$

\section{Conclusion}

At the present time, no single method of imaging the urinary tract provides answers to the essential questions. Ultrasonography alone appears to be inadequate and even misleading in the investigation of the child with UTI. The DMSA study can identify renal involvement that only follow up or a later IVU will resolve into acute and reversible or permanent renal change. Initial contrast cystography will identify the presence and severity of VUR and visualise the urethra. The IVU will provide a structural assessment of the urinary tract, Clearly the skills of performing and interpreting the IVU are of immense importance and should not be lost; earlier multiple film procedures need modification to reduce radiation exposure.

All children with UTI require investigation, ideally after the first urinary tract infection, by at least two imaging techniques. With the changes taking place in current practice, there will often be a need for consultation between the clinician and imaging specialist to decide on the optimal investigations for the individual child.

We are grateful for the support of the National Kidney Research Fund and the Children Nationwide Medical Research Fund, for the help of Sisters Jo March and Moira Clarke in the clinics and for the secretarial help of Mrs Jan Port.

1 Working Group of the Research Unit, Royal College of Physicians. Guidelines for the management of acute urinary tract infection in childhood. $f R$ Coll Physicians Lond 1991; 25: 36-42.

2 Haycock GB. A practical approach to evaluating urinary tract infection in children. Pediatr Nephrol 1991; 5: tract 2 .

3 Koff SA. A practical approach to evaluating urinary tract infection in children. Pediatr Nephrol 1991; 5: tract infecti

4 Whyte KM, Abbott GD, Kennedy JC, Maling TMJ. A protocol for the investigation of infants and children with urinary tract infection. Clin Radiol 1988; 39 278-80.

5 Gordon I. Urinary tract infection in paediatrics: the role of diagnostic imaging. Br F Radiol 1990; 63: 507-11.

6 Smellie JM, Rigden SPA. Pitfalls in the investigation of children with urinary tract infection. Arch Dis Child 1995, 72: 251-8.

7 Jacobsson B, Nolstedt L, Svensson L, Soderlundh S, Berg U. $99 \mathrm{~m}$ Technetium-dimercapto succinic acid scan in the diagnosis of acute pyelonephritis in children: relation to clinical and

8 Rickwood AMK, Carty HM, McKendrick T, et al. Current imaging of childhood urinary infections: prospective imaging of childhood urinary

9 Smellie JM, Poulton A, Prescod NP. Retrospective study of children with renal scarring associated with reflux and children with renal scarring associated with

10 urinary infection. BMF 1994; 308: 1193-6. reflux. Br f Urol 1990; 65: 403-6.

11 Gordon AC, Thomas DFM, Arthur RJ, Irving HC, Smith SEW. Prenatally diagnosed reflux: a follow-up study. Br f Urol 1990; 65: 407-12.

12 Atwell JD, Cook PL, Strong L, Hyde I. The interrelationship between vesico-ureteric reflux, trigonal abnormalities and a bifid pelvicalyceal collecting system in a family study. Br F Urol 1977; 49: 97-107.

13 Andrich MP, Majd M. Diagnostic imaging in the evaluation of the first urinary tract infection in infants and young children. Pediatrics 1992; 90: 436-41. 